\title{
Communicability problems on MOOCs: a study around metacommunication
}

\author{
Beatriz B. do Rêgo ${ }^{1}$, Filipe A. Garrido ${ }^{1}$, Jean C. S. Rosa ${ }^{1}$, Ecivaldo S. Matos ${ }^{1}$ \\ ${ }^{1}$ Departamento de Ciência da Computação (DCC) - Instituto de Matemática e \\ Estatística (IME) - Universidade Federal da Bahia (UFBA) \\ Salvador - BA - Brasil \\ \{beatrizbr, filipe.garrido, jean.rosa, ecivaldo\}@ufba.br
}

\begin{abstract}
The MOOCs emerged as instruments for education democratization by free online courses. However, MOOCs have a high dropout rate for their students. In this sense, this paper presents some results about whether communicability problems are related to the general causes of dropout in MOOC courses. In order to reach this objective, the Semiotic Inspection Method was applied in Coursera and EDx MOOC platforms. From the results, it was inferred that communicability problems are associated with some of the general causes that lead to the abandonment or the withdrawal of students in MOOCs.
\end{abstract}

\section{Introduction}

MOOC (Massive Open Online Course) is a kind of open and online course that no have a predefined number of students [Fassbinder, Delamaro, Barbosa 2014]. This kind of course has attracted students of different ages, background, and nationalities [He et al. 2015]. But it has received some critics as the high dropout rate of its students [Onah et al. 2014].

The general causes of the high dropout rate in MOOCs may be related to social and pedagogical factors, motivation, personal or professional aspects, or technological problems. From the technological viewpoint, the inability of some students to use computational tools and environments could be directly or indirectly related to the abandonment of students in MOOC, as the literature presents [Bezerra, Da Silva 2017].

Bezerra and da Silva (2017) realized that the quality of interaction design of MOOC platforms interferes in the interactive and pedagogical processes. In [Do Rêgo, Monteiro, Sampaio 2017], the authors emphasize that users didn't use some MOOCs functions because the system did not have high metacommunication quality. In this sense, communicability is one of the quality attributes of human-computer interaction (HCI) - such as usability and accessibility.

According to Fini (2009), one of the attributes of MOOC is to be open. However, users must have minimal skills, among them, to be able to use interactive computational technologies. This cause was cited in a study on the Coursera platform, reporting the limitations of the technologies as one of the reasons for abandonment by students enrolled [Gomez-Zemero, La Garza 2016]. This reason was identified by analysis of messages of discussion in pedagogical forums in the Coursera platform. 
In this sense, this paper presents results of communicability evaluations through the semiotic inspection method (SIM) [De Souza, Leitão 2009] of the Coursera and EDx platforms, whose objective was to investigate whether problems in the quality of interaction (human-computer) could be related to the causes of general of abandonment found in the scientific literature [Bezerra, Da Silva 2017].

This paper was organized in five more sections. In the second section we present the theoretical foundation, and the general causes of abandonment in MOOC. In the third section we present the methodology adopted. The results obtained are presented in the fourth section. Finally, the last section has our final considerations and suggestions for MOOC design focusing on system communicability.

\section{Theoretical Foundation}

In this section we present the concept of communicability, metacommunication, MOOC, and the general causes of abandonment in MOOC that may be related to the metacommunication quality.

\subsection{Communicability \& Metacommunication}

All parts of an interactive computer system are constructed by signs that need to be interpreted by the user so that for the interaction may be occur. However, during interaction with computer systems, there are two distinct actors and their interpretations: the designer and the user.

Given the need for users to interpret the signs created by designers, the Semiotic Engineering considers that the interaction process (in $\mathrm{HCI}$ ) is a communicative process between designer and user through the interface De Souza (2005). In this sense, the Semiotic Engineering define communicability as the ability of an interactive computational artifact to (meta)communicate to users. The Figure 1 exemplifies this interaction process from point of view of Semiotic Engineering.

Metacommunication is composed of messages to: identify the profile of the user; identify what he/she wants or needs to do; and inform the way he/she prefers, wants and needs to interact [De Souza 2005]. From this perspective, the Semiotic Engineering epistemology is not centered on how users interact with computers, but how users communicate with designers through their interaction time representative, that is, a Communication-Centered Design.

For this research, we decided to perform firstly the communicability evaluation through Semiotic Inspection Method (SIM), a method to metacommunication reconstruction by designer's communication perspective [De Souza, Leitão 2009], to identify communication problems from designer perspective, and relate them to the abandonment causes in MOOC. Details of the methodological procedure are presented in Section 3. 


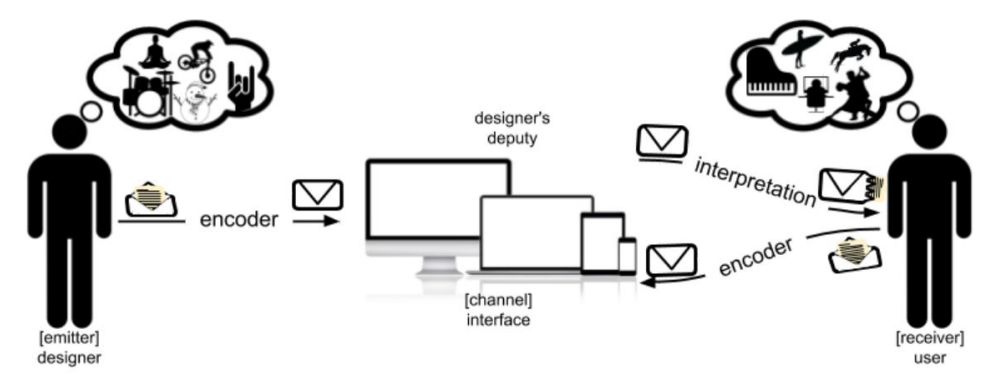

Figure 1. Metacommunication process [Rosa, Matos 2016]

\subsection{General Causes of dropout in MOOC}

According by literature, the expression Massive Open Online Courses - MOOC - was created in 2008, by Dave Cormier, to describe a particular online course model developed by Stephen Downes and George Siemens [Grainger 2013]. MOOCs are considered as innovative educational resources. However, it has a high dropout rate of its students [He et al. 2015; Onah et al. 2014; Baloi 2009; Clow 2013; Alario-Hoyos, et al. 2013]. Although thousands of students are enrolled at all times, the completion rate for most courses ranges from $10 \%$ to $25 \%$ [Onah et al. 2014].

In 2012 several MOOC platforms were launched [Grainger 2013]. Coursera, EDx and Udacity are examples of these platforms [Daniel 2012]. They offer free partnerships with several public and private universities and have become today's leading MOOC platforms [Daniel 2012]; but their courses on with the high dropout rate.

Bezerra and Silva (2017) identified 24 (twenty-four) general causes that led students to dropout MOOC courses (see list below). We considered that eleven (11) of them are related to the quality of metacommunication in MOOC, because they indicate problems of designer-user communication. These specific ones are highlight in bold [1, $2,3,6,7,8,11,12,14,22$ and 24] for their direct relation with our objective.

1. Lack of social interaction and cooperative activity between the students and group work

2. Lack of motivation on the part of the students

3. Lack of sufficient time to dedicate to the course/difficulty in time management

4. Difficulties in relating concepts with applications

5. The level of the course is different from the original expectations

6. Assessment model

7. Limitations on the use of Information Technology (IT)

8. The quality of materials - videos and exercises

9. Lack of maturity of the student

10. High workload
11. Difficulty to follow the course content

12. Lack of a tutorial to guide users

13. Enrolment in more than one course

14. Difficulties with the English Language

15. The course does not meet my expectations

16. Time Zone difference

17. Free of cost for the student

18. Lack of admission process

19. Delay in starting the course

20. Learning only one or more topics of the course

21. Lack of urgency or pressure to end the course

22. Lack of feedback activities

23. Lack of prior knowledge and preparation on the part of the students

24. Heterogeneity of the students profile

We have used three of that causes to illustrate how abandonment can be influenced by communicability: (i) heterogeneity of the students profile; (ii) difficulties with the English Language; and (iii) lack of feedback activities. 
MOOC are courses that have massive participation with great heterogeneity of students. One of the characteristics of heterogeneity is attributed to cultural difference, because on system developed, the designer ideology and aspects of his culture are disposed in the interface. Users and designers use signs according their cultural contexts [Rosa, Matos 2016]. In a MOOC, the interpretation of the interaction signs may be different by each student because it has no defined a student profile; MOOC is for all people. So, the metacommunication should be wide enough to permit different student's profiles to understand the designer's speech close to him.

This can influence their understanding of the signs arranged at the interface, which may lead to the abandonment of the students, directly or indirectly. Faced with this cultural difference, another related aspect is that students do not always precisely understand the language of MOOC platform.

The lack of feedback makes the experience of a massive course become paradoxical, because MOOCs have thousands of participants who do not interact with each other, performing an individual and solitary (self-directed) course. Depending on the course and platform the interaction between peers is not possible, indirectly correlating this general cause lack of motivation on the part of the students. Therefore, the environment (interface) and the student must "talk" so that there is effectively this interaction. If the platform does not facilitate activities that provide feedback, it is a metacommunication failure.

Consistent with these causes, interface inspection through the SIM examines whether MOOC platforms are effective and efficient in their communication or not. Details about the SIM are presented in the next section.

\section{Methodology}

The communicability evaluation (by SIM) of Coursera and EDx was carried out in four stages: (i) semiotic inspection of the Coursera platform; (ii) semiotic inspection of the EDx platform; (iii) comparative analysis of results; and (iv) drafting suggestions for best design practices for the development of a MOOC platform.

Scenarios were created in order to make feasible the SIM, as indicated in [De Souza, Leitão 2009]. The scenarios "describe human activities or tasks in a history that allows the exploration and discussion of contexts, needs, and requirements" [Preece, Rogers, Sharp 2013]. The same scenarios were used in the inspection of both platforms. The scenarios used are (i) user registration, (ii) course selection, (iii) beginning of the course e (iv) participation in the forum.

After the scenarios were defined, the interface of Coursera and EDx was inspected. During the inspection, the classification of different types of interface's signs was used as a criterion for the organization of the results.

\subsection{SIM Process}

According to the protocol established by SIM, three categories of signs were analyzed: metalinguistic, static and dynamic [Barbosa, Silva 2010].

Static signs express the state of the system, whose meaning is interpreted 
VIII Congresso Brasileiro de Informática na Educação (CBIE 2019)

Anais do XXX Simpósio Brasileiro de Informática na Educação (SBIE 2019)

independently of causal and temporal relations of the interface; for example, the menu items, the buttons of a toolbar, the fields and the buttons of a form, among others [Barbosa, Silva 2010].

Dynamic signs are signs that express the behavior of the system, involving temporal and causal aspects of the interface. They are linked to the interaction itself and should be interpreted by reference to it. For example, the possibility of dragging items from one screen to another, the causal association between choosing a menu item and displaying a dialog [Barbosa, Silva 2010].

Finally, metalinguistic signs are used by the designer to explicitly communicate to users the meanings he/she assigned to the other signs encoded in the interface, and how they should be used. Examples are error messages, dialogues, warnings, manuals, help, among others [Barbosa, Silva 2010]. For each class of sign was rebuilt the designer's metamessage, according to De Souza and Leitão (2009) template, namely:

Here is my understanding of who you are, what I've learned you want or need to do, in which preferred ways, and why. This is the system that I have therefore designed for you, and this is the way you can or should use it in order to fulfill a range of purposes that fall within this vision.

At the end of the inspection of each platform, the results were consolidated, in which the evaluator summarizes the ruptures found in the platform. Identifying the sign elements referring to the prior knowledge required and imposed by the platform for navigation through its interface; beyond the knowledge acquired after navigation/inspection of the system.

\section{Results}

The results are described in the subsections separated by platform that present the respective reconstituted metamessages for each category of signs.

\subsection{Coursera Inspection}

Three meta-messages related to metalinguistic, static and dynamic signs are presented in this order. They highlight only those disruptions that have been correlated with the general causes of neglect [Do Rêgo, Garrido, Matos 2017] and best practices for developing a MOOC. Below is described the meta-message regarding the metalinguistic signs identified in the Coursera platform inspection.

[You are a user who aims to learn and is looking for the best online courses available on the internet in order to reach it. You are a person who knows the term MOOC and is looking for a course that is classified as MOOC. But understand that the platform you chose to pursue the course does not have a specific category for MOOC. [...]. You understand the English language and realize by logging into the system that you were on the right path to finding what you were looking for. [...] However, you always need reminders and course information so you can complete it, as well as incentives to actively participate in discussion forums on each module.]

By means of the SIM, it was identified the translation faults of the interface elements, related to the metalinguistic signs. The user sets the desired language, but excerpts of the platform remain in the default language (English). Coursera platform 
VIII Congresso Brasileiro de Informática na Educação (CBIE 2019)

Anais do XXX Simpósio Brasileiro de Informática na Educação (SBIE 2019)

offers several shortcuts to the help center. However, English is the predominant language, even on interfaces translated into other languages. If the user is not familiar with the language, he can leave the course.

Following the reconstructed metamessage regarding the inspection of the static signs, following the same format fragmented with the evidence of the Coursera platform inspection:

[You are a user who uses the knowledge acquired from other systems, especially those of the same domain, educational. Knowing this, we use common symbols and colors from your everyday life to guide you. You are a user who wants to run a MOOC but does not want to be charged for it. [...] ].

At the beginning of the course, it was noticed that the video caption was not synchronized. To solve the problem it was necessary to identify the static symbol of a white flag associated with the evaluators with a help signal. But depending on the user's profile may not understand the symbol and doesn't ask for help to correct this synchronization failure. Figure 2 presents the problem-related.

And finally, the metamessage reconstructed from the dynamic signs for the three tasks carried out in the platform Coursera follows:

[You are a user that before starting a course I would like to have a preview of how this course will be held. [...]. You are a user who is accustomed to accompany the execution of your course through a calendar so that as you carry out the tasks you can follow your progress. As well as the remaining time for you to complete the entire module available.]

In the inspection of the dynamic signs, it was possible to visualize the existence of a symbol informing how many minutes are left to complete each module. The information was represented by an open book with the phrase "nothing expired." This symbol may indicate to the student that the material of the course is limited in time. Corresponding to the reason for abandonment due to lack of time, the user would have to do everything possible to finalize the module before the time of access to the material expires.

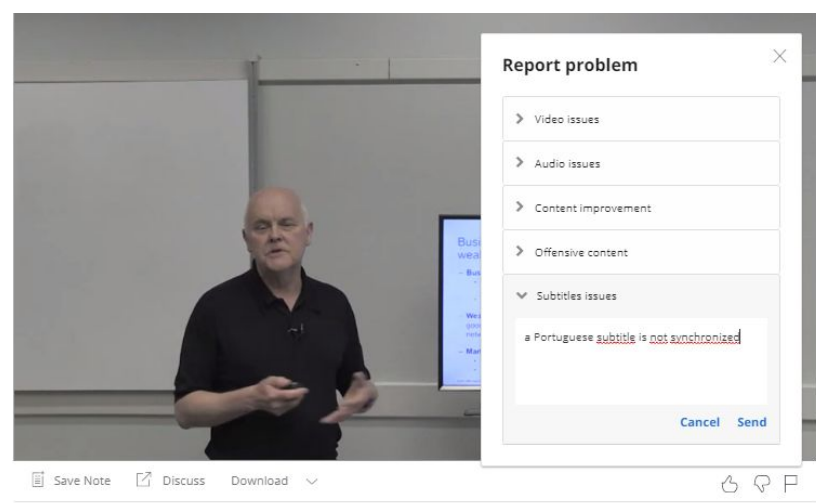

Figure 2. Report video error

\subsection{EDx Inspection}

In this subsection are presented the metamessages referring to the inspection of the EDx platform. Described in the same order as the Coursera evaluation. There follows, then, the metamessage from the metalinguistic signs. 
VIII Congresso Brasileiro de Informática na Educação (CBIE 2019)

Anais do XXX Simpósio Brasileiro de Informática na Educação (SBIE 2019)

[You are a student who aims to have quick access to the knowledge available on MOOC platforms and needs access at any time and place. [...] You are a user that when searching and checking the list of courses that were returned in the search, you will not feel the need to access the help center, because this action is impossible in the system. [...] A user who does not want to identify himself when asking a question in the discussion forum of the MOOC course that participates. [...]]

A communicability breakdown found is the number of languages available for translation from the platform. EDx supports two languages, English and Spanish. However, several courses are available in other languages. When was selected the course wanted, some parts of content were in the language of the platform, another ones were in the original language of the course. It should cause communication breaks during the interaction process.

Another breakdown could be caused by the difficulty to access the help center of the platform. The associated menu is just situated at the bottom of the page. This can hinder access to functionality. The evaluator searched for a course but returned a list with a significant amount of available courses. Rolling the sidebar to gain access to the help center was not feasible. At the finish of the page, the courses for the initial survey were loaded.

A feature provided by the EDx alerted to the use of a descriptive table of the symbols - Figure 3 - (signs) that make up the discussion forum, called a glossary of signs (emphasis ours). This framework is intended to facilitate the user's understanding of the features and functions of the EDx discussion forum.

The composition of the metamessage emitted by the designer is described from the perspective of the static signs in the next highlighted section.

[You are a user who uses the knowledge gained from other interfaces, but you know that some signs used in this platform have their own definition. [...] A user understands that the platform developed does not use patterns to aid in their interaction, [...].]

EDx platform does not use patterns for the representation of the sign, including the colors of the buttons. At times, the magnifier symbol has different meanings and attributed functions; in some cases, it is used as a search button, in others, it acts as a search bar recognition symbol.

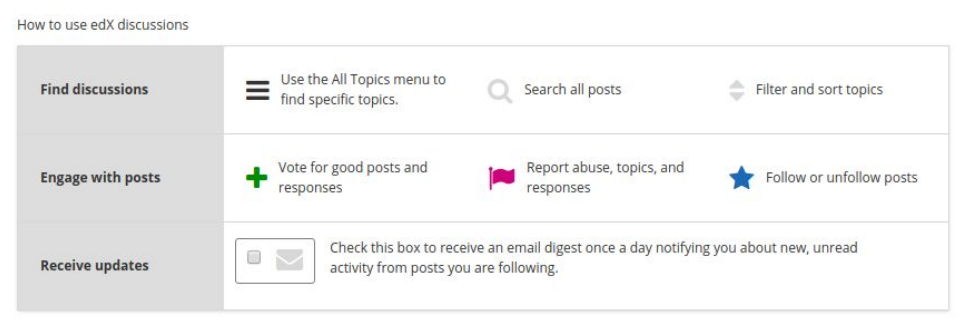

Figure 3. Glossary of signs - EDx

Another symbol with confusing interpretation is the document, located on the presentation page of the course chosen after the search, which denotes a file to download, possibly a text. However, this perception is misleading since the symbol presents a more detailed description of the course. A similar case occurs with the flag symbol in the glossary, indicating a request for help. But, the action executed when 
VIII Congresso Brasileiro de Informática na Educação (CBIE 2019)

Anais do XXX Simpósio Brasileiro de Informática na Educação (SBIE 2019)

executed is to report the abuse of topics or responses.

The difficulty of the user in perceiving his current state in relation to the totality of the course demonstrates the omission of important information. In the following section, we present the metamessage identified from the inspection of the dynamic signs in the platform EDx.

[[...] A user who enjoys receiving visual feedback from the system to identify where the interface is. However, he realizes that these signs do not have a pattern, confusing their interpretations. The user accesses the video content without requesting play, due to its automatic start.]

EDx provides a number of dynamic effects to situate your user. The interaction received several visual incentives, guiding the place where the menus, links, buttons are located. A facilitator identified was the video content described next to the playback window. The student (user) will have access to the content without having to request the execution, the video was started automatically. When the video starts its content stands out, moving dynamically, favoring the understanding.

\subsection{Comparative Analysis of Results}

In both MOOCs platforms it was possible to identify similarities in the representation of the signs arranged in the interface, possibly to reduce the impact in case of user migration. Some ruptures identified in the general causes of abandonment of Bezerra and da Silva (2017) were found in both.

The first similarity identified was on the main page in which the two platforms use as background image a woman in a situation similar to the students of the courses. The difference is with the phrase "Make the best online courses!" and the use of the notebook in the Coursera, while in the EDx the woman uses a smartphone and the phrase "Accelerate your future. Learn anytime, anywhere.". These metalinguistic signs indicate the pretension of each platform in the approach with (potential) students.

The difficulty of accessing the help center in EDx does not occur in Coursera. Accessing this EDx environment found no way to return to the main page of the platform through the system interface, only with the web browser feature. This fact is considered a serious breach of communicability.

Among the divergences of signals, the flag that requests help in the Coursera, serves to denounce the abuse of rules in the forum of the EDx. It is suggested that another symbol be used to indicate the action of reporting an abuse of rules in the EDx discussion forum.

It is believed that these ruptures are directly related to the general causes of abandonment, being possibly indirect causes. Associated with other general causes may favor the dropping off. The difficulty in correctly translating the interface occurred on both MOOC platforms, it is one of the main problems identified in the inspection. The limitations in the use of information technologies, difficulty in accessing the help desk in the EDx, and finally, the problem of the synchronization of the legend in the Coursera were other ruptures of communicability found.

The difficulty of time management (Bezerra and da Silva, 2017) was correlated 
to the ruptures identified in both platforms. In Coursera, dynamic signals denote that the course has a limit of availability for access, pressing the student's time management. EDx does not adequately present course progress and may induce students to have problems managing their time.

In the EDx occurs an incentive to create topics in the forum of each module, encouraging the interaction between the students and the evaluation in pairs. This, in turn, does not occur in Coursera, which directs the student to the main page of the course if you want to use the forum.

\section{Final Considerations}

In this paper, the results of the communicability evaluation were presented, through the application of the Semiotic Inspection Method (SIM) in two MOOC platforms, Coursera and EDx, with the objective of investigating if there were ruptures of communicability potentially related to the general causes of student abandonment in MOOC. Some clues have been found and should be used in future work to guide interaction design and instructional design strategies for MOOC platforms and courses. In addition, other MOOC platforms will be evaluated and the results compared.

Listed the best practices for the design of a MOOC platform from the results of this study. Are they: (i) ease of access to the system help center, being able to access all MOOC pages; (ii) standardization of buttons and warning signs; (iii) a forum topic at the end of each module, to encourage student interaction; (iv) standardization of platform language (full translation, when applicable); (v) use of easily recognizable signs commonly used in other (inherited) systems; (vi) progress bar visible on the main course page; and (vii) content of the course.

This will not solve the problem of high dropout rates in MOOC courses, especially since not all the general causes indicated in the literature are strongly related to technological aspects, but the improvement of the technological environments supporting MOOC can favor the permanence and conclusion of courses by some students.

We expect this paper could be useful as a guideline for MOOC platform development, and an indicator of the influence of the quality of metacommunication on the abandonment of students in MOOC. It should be noted that the two inspected platforms have a considerable number of students and high dropout rates in their courses.

\section{References}

Alario-Hoyos, C., Pérez-Sanagustín, M., Delgado-Kloos, C., Muñoz-Organero, M., e Rodríguez-de-las Heras, A. (2013). Analysing the impact of built-in and external social tools in a MOOC on educational technologies. In European Conference on Technology Enhanced Learning. Springer. pp. 5-18.

Baloi, J. A. (2009). A concepção da educação democrática na obra "Democracia e Educação" de John Dewey. Monografia-Faculdade de Filosofia e Ciências Humanas da Universidade São Tomás de Moçambique, Maputo. 
VIII Congresso Brasileiro de Informática na Educação (CBIE 2019)

Anais do XXX Simpósio Brasileiro de Informática na Educação (SBIE 2019)

Barbosa, S. e Silva, B. (2010). Interação humano-computador. Elsevier.

Bezerra, L. N. M. e da Silva, M. T. (2017). A review of literature on the reasons that cause the high dropout rates in the MOOCs. Revista Espacios, v. 38, n. 5.

Clow, D. (2013). MOOCs and the funnel of participation. In Proceedings of the Third International Conference on Learning Analytics and Knowledge, pp. 185-189. ACM.

Daniel, J. (2012). Making sense of MOOCs: Musings in a maze of myth, paradox and possibility. Journal of interactive Media in education, n. 3 .

De Souza, C. S. (2005). The semiotic engineering of human-computer interaction. MIT press.

De Souza, C. S. e Leitão, C. F. (2009). Semiotic engineering methods for scientific research in hci. Synthesis Lectures on Human-Centered Informatics, 2(1):1-122.

Do Rêgo, Beatriz Brito, Filipe Garrido, Ecivaldo Matos. (2017). Identifying influences of the quality of interaction on dropout rates of MOOC: preliminary results. Brazilian Symposium on Computers in Education (Simpósio Brasileiro de Informática na Educação-SBIE). v. 28. n. 1. pp 1766-1768.

Do Rêgo B. B., Monteiro I. T., Sampaio A. L. (2017). Communicability evaluation of privacy settings on Facebook for Android. In: International Conference on Human-computer Interaction. Springer, Cham. v. 10292. pp. 623-639.

Fassbinder, A., Delamaro, M. E., e Barbosa, E. F. (2014). Construção e uso de moocs: Uma revisão sistemática. Brazilian Symposium on Computers in Education (Simpósio Brasileiro de Informática na Educação-SBIE), v. 25, pp. 332-341.

Fini, A. (2009). The technological dimension of a massive open online course: The case of the CCK08 course tools. The International Review of Research in Open and Distributed Learning, v. 10, n. 5, pp. 1-26.

Grainger, B. (2013). Introduction to MOOCs: avalanche, illusion or augmentation. Policy Brief - UNESCO (july). Institute for Information Technologies in Education. URL: http://iite.unesco.org/pics/publications/en/files/3214722.pdf.

Gomez-Zermeno, M. G., De La Garza, L. A. (2016). Research analysis on mooc course dropout and retention rates. Turkish Online Journal of Distance Education, v. 17, n. 2, pp. 3-14.

He, J., Bailey, J., Rubinstein, B. I., e Zhang, R. (2015). Identifying at-risk students in massive open online courses. In AAAI, pp. 1749-1755.

Onah, D. F., Sinclair, J., e Boyatt, R. (2014). Dropout rates of massive open online courses: behavioural patterns. EDULEARN14 Proceedings, pp. 5825-5834.

Preece, J., Rogers, Y., e Sharp, H. (2013). Design de Interação: Além da interação humano computador. Bookman, $3^{\circ}$ edition.

Rosa, J. C. S., Matos, E. (2016). Semio-Participatory Framework for Interaction Design of Educational Software. In Proceedings of the 15th Brazilian Symposium on Human Factors in Computing Systems (IHC '16). ACM. [s. p.]. 